\title{
P01-029 - Microscopic hematuria in FMF
}

\author{
L Grabowitz ${ }^{1,2}$, OL Kukuy ${ }^{3 *}$, M Lidar ${ }^{1,2,4}$, I Ben Zvi ${ }^{2,4}$, O Feld ${ }^{2,4}$, Y Kesel ${ }^{4}$, A Livneh ${ }^{1,2,4}$
}

From 7th Congress of International Society of Systemic Auto-Inflammatory Diseases (ISSAID)

Lausanne, Switerland. 22-26 May 2013

\section{Introduction}

Hematuria is a recognized feature of familial Mediterranean fever (FMF), but its prevalence and clinical, genetic and demographic correlates are not known.

\section{Objectives}

To study the rate and features of microscopic hematuria in FMF.

\section{Methods}

We studied consecutive FMF patients, who came for a pre-scheduled follow up visit in the FMF clinic for the presence of microscopic hematuria, defined as $\geq 5 \mathrm{RBC} / \mathrm{HPF}$ or $\geq 25 \mathrm{RBC} / \mu \mathrm{l}$ in urine analysis performed during remission, recorded at least once in the 3 previous clinic visits. Exclusions were known kidney, urinary tract, prostate or gynecologic diseases, bleeding or thrombotic diatheses, pregnancy or menstruation, intensive physical activity and anticoagulant/platelet treatments. Patients presenting with hematuria were compared to patients without hematuria for various clinical, genetic and demographic parameters, using a questionnaire, patient files, and an interview.

\section{Results}

The frequency of microscopic hematuria among FMF patients was found to be $17 \%(30 / 173)$, not conspicuously higher than in the general population (1-16\%). Hematuria was associated with higher levels of acute phase reactants during the attack-free phase, and higher rates of a history of vasculitides: protracted febrile myalgia and Henoch Schonlein Purpura. There were no differences in the distribution of severity scores among patients of the hematuria and control groups. The rate of homozygosity to M694V and the rate of 2 affected MEFV alleles was similar to that of the control group.

${ }^{3}$ Institute of Nephrology and Hypertension, Sheba Medical Center Tel HaShomer, Ramat Gan, Israel

Full list of author information is available at the end of the article

\section{Conclusion}

This study could not confirm the notion that microscopic hematuria is more common in FMF. However, its occurrence may reflect an active disease and renal vascular inflammation

\section{Disclosure of interest}

None declared.

\section{Authors' details}

${ }^{1}$ Sackler School of Medicine, Tel Aviv University, Tel Aviv, Israel

. ${ }^{2}$ Heller Institute of Medical Research, Israel. Institute of Nephrology and Hypertension, Sheba Medical Center Tel HaShomer, Ramat Gan, Israel. ${ }^{4}$ Medicine F, Sheba Medical Center Tel HaShomer, Ramat Gan, Israel.

Published: 8 November 2013

doi:10.1186/1546-0096-11-S1-A33

Cite this article as: Grabowitz et al:: P01-029 - Microscopic hematuria in FMF. Pediatric Rheumatology 2013 11(Suppl 1):A33.

\section{Submit your next manuscript to BioMed Central and take full advantage of: \\ - Convenient online submission \\ - Thorough peer review \\ - No space constraints or color figure charges \\ - Immediate publication on acceptance \\ - Inclusion in PubMed, CAS, Scopus and Google Scholar \\ - Research which is freely available for redistribution

C Biomed Central

(c) 2013 Grabowitz et al; licensee BioMed Central Ltd. This is an Open Access article distributed under the terms of the Creative Commons Attribution License (http://creativecommons.org/licenses/by/2.0), which permits unrestricted use, distribution, and reproduction in any medium, provided the original work is properly cited. 